\title{
The effect of overtraining on a visual discrimination on transfer to a spatial discrimination*
}

\author{
T. GARY WALLER \\ University of W'aterloo, W'aterloo, Ontario, Canada
}

\begin{abstract}
Rats were first either trained to criterion or given overtraining on an orientation discrimination and then were given an extradimensional shift to a position discrimination. Overtraining on the visual discrimination facilitated performance on the position discrimination. Implications for mediational theories of discrimination learning were indicated.
\end{abstract}

Two-process theories of discrimination learning (Zeaman \& House, 1963; Sutherland \& Mackintosh. 1971; Lovejoy, 1968) suggest that, in order to solve a discrimination problem, an organism first must learn to attend to relevant cues and then must learn an appropriate instrumental response. Presumably, overtraining, as compared to criterion training only, on a discrimination increases the strength of attention to relevant cues and decreases attention to irrelevant cues. Thus, overtraining should facilitate subsequent performance on an intradimensional (ID) shift, where the original relevant dimension is relevant, but should hinder performance on an extradimensional (ED) shift. where a new dimension is relevant. However. Sutherland and Andelman (1969) and Waller $(1970,1971)$ found that overtraining facilitated performance on ED shifts where the relevant acquisition cues were not variable and irrelevant during transfer. Within the mediational framework, one interpretation (cf. Sutherland \& Andelman, 1969; Wagner, 1969) of the facilitation is that overtraining weakens attention to other irrelevant cues, such as position of reward (e.g., left or right). that are present both in acquisition and in transfer. If overtraining on a visual discrimination reduces attention to position cues, thus facilitating performance on a subsequent ED shift to another visual dimension, then overtraining on a visual discrimination should interfere with a subsequent ED shift to a position discrimination.

Rats first were trained on a stripe-orientation (left vs right oblique) discrimination and then. following criterion training or overtraining, on a position discrimination. In Experiment 1, there were no orientation cues present during the transfer phase: in Experiment 2, new values (horizontal and vertical) on the orientation dimension were irrelevant and were variable within trials. The new values were introduced to preclude confounding of negative transfer of the

\footnotetext{
*This research was supported by Grant AO-326 from the National Research Council of Canada. Requests for reprints should be sent to the author at the Department of Psychology. University of Waterloo, Waterloo, Ontario, Canada.
}

instrumental response (approaching left or right oblique) with negative transfer of the mediating response (attending to orientation). It was expected that overtraining would produce a decrement in performance in both experiments, particularly in Experiment 2 with variable irrelevant orientation cues.

\section{METHOD}

The Ss were two shipments of 16 male albino rats each. supplied by the Holtzman Co., Madison. Wisconsin, and were approximately 100 days old upon arrival at the laboratory. The apparatus was the discrimination box described by Waller (1970) and consisted of a start section. a triangular-shaped choice area. and two adjacent goalboxes. Four stinulus inserts for the rear walls of the goalboxes were covered with alternating black and white stripes, $2.54 \mathrm{~cm}$ wide, oriented horizontally, vertically. $45 \mathrm{deg}$ to the left of vertical. or $45 \mathrm{deg}$ to the right of vertical.

On arrival. Ss were housed individually and given ad lib food and water for 3 days. Then. to reduce the possibility of drive confounds due to differential weight changes in the treatment groups (cf. (layton. 1965). each S was placed on a once-daily ration of $10-12 \mathrm{~g}$ of laboratory cubes to maintain a constant 85 $( \pm 15 \mathrm{~g})$ of terminal ad lib weight for the remainder of the experiment. Following the ad lib period, each $S$ received 5 days of prehandling and was permitted access to five .045-g Noyes pellets located in a glass dish in the center of the prehandling box. On the day following pretraining. each $\mathrm{S}$ was given one exposure to the discrimination box with no stimulus inserts present. with all doors open, and with five pellets in each goal. S was left in the box for $3 \mathrm{~min}$ or until all pellets were eaten. whichever came first. If no pellets were eaten after $90 \mathrm{sec}$. the doors leading to the foodcups were held open by $\mathrm{E}$. The procedure was repeated daily until each $S$ ate all 10 pellets. The first goalbos entered on the first pretraining trial was taken as an indication of S's position preference.

Following prehandling. each $S$ received acquisition training on a simultaneous discrimination with orientation of stripes (left or riglit) as the relevant cue. lior half the $S$ s, left was positive $(S+)$ : for the other half, right was $S+$. Training was with a rerun noncorrection procedure (cf. Warren \& McGonigle. 1969; Sutherland \& Mackintosh, 1971. p. 26) such that if $S$ made an error, the location of $S+$ was not changed for the next trial. If $S$ made a correct response. the probability was 0.5 that $S+$ would be moved according to randomly selected Gellerman series (Hilgard, 1951). Ss were run each day until they made a total of 10 correct responses, except on Days 1.2. and 3. when thes were run to 2. 3. and 5 correct responses. respectively. Acquisition training continued for each $\mathbf{S}$ until he made 13 
Table 1

Mean Trials to Criterion During Transfer

\begin{tabular}{|c|c|c|c|}
\hline \multirow{2}{*}{$\begin{array}{c}\text { Irrelevant } \\
\text { Cues in Transfer } \\
\end{array}$} & \multirow{2}{*}{$\begin{array}{c}\text { Positive } \\
\text { Position } \\
\text { in Transfer }\end{array}$} & \multicolumn{2}{|c|}{$\begin{array}{c}\text { Amount of } \\
\text { Acquisition Training }\end{array}$} \\
\hline & & Criterion & Overtrained \\
\hline $\begin{array}{l}\text { None } \\
\text { Experiment I }\end{array}$ & $\begin{array}{l}\text { Preferred } \\
\text { Nonpreferred }\end{array}$ & $\begin{array}{l}31.80 \\
56.67\end{array}$ & $\begin{array}{l}34.00 \\
41.80\end{array}$ \\
\hline $\begin{array}{l}\text { Variable } \\
\quad \text { Experiment II }\end{array}$ & $\begin{array}{l}\text { Preferred } \\
\text { Nonpreferred }\end{array}$ & $\begin{array}{l}19.25 \\
44.25 \\
\end{array}$ & $\begin{array}{l}26.25 \\
27.00 \\
\end{array}$ \\
\hline
\end{tabular}

correct responses in any 15 consecutive trials. Reward for a correct response was five pellets; Ss were confined in the goalbox for $5 \mathrm{sec}$, and the within-day intertrial interval was approximately $10 \mathrm{sec}$. On the day following acquisition criterion, half the $S$ s were transferred to a position discrimination; the other half received an additional 150 trials (10 per day) on the orientation discrimination. During overtraining, procedures were the same as in acquisition.

During transfer, half the $S s$ were rewarded for choosing their preferred position (as indicated by the position chosen during pretraining) and half were rewarded for choosing the nonpreferred position. The resulting design contained four major groups: two criterion-trained groups, one transferred to the preferred side (Group CP) and one to the nonpreferred side (Group $\mathrm{CN}$ ), and two overtrained groups, one transferred to the preferred side (Group OP) and one to the nonpreferred side (Group ON). In Experiment 1, there were no orientation cues present in the discrimination box. In Experiment 2, two new values (horizontal and vertical) on the orientation dimension were variable irrelevant, i.e., both values were present on each trial and each cue appeared equally often in each position (cf. Shepp \& Turrisi, 1966). Training was by the noncorrection procedure, but all other procedures were the same as in acquisition.

\section{RESULTS AND DISCUSSION}

In Experiment 1, neither mean trials to acquisition criterion (138.88) nor mean errors during overtraining (10.50) were affected by any treatment condition. Mean trials to transfer criterion are shown in Table 1. Analysis of variance indicated a significant interaction between amount of acquisition training and direction of transfer training $(F=7.31$, df $=1 / 12, p<.05)$. The interaction was due to the fact that Group $\mathrm{CN}$ made significantly more errors than Group $\mathrm{CP}(\mathrm{F}=21.00, \mathrm{df}=1 / 12$, $p<.01)$ or Group $\mathrm{ON}(\mathrm{F}=7.51, \mathrm{df}=1 / 12, \mathrm{p}<.05)$, but Groups $O N$ and OP did not differ $(F=2.07, \mathrm{df}=$ $1 / 12$ ). In Experiment 2, neither mean trials to acquisition criterion (179.00) nor mean errors during overtraining (31.62) were affected by any treatment. As in Experiment 1, analysis of variance of trials to transfer criterion (see Table 1) indicated a significant interaction $(\mathrm{F}=10.34, \mathrm{df}=1 / 12, \mathrm{p}<.01)$, such that Group $\mathrm{CN}$ made more errors than did Group $\mathrm{CP}(\mathrm{F}=21.99$, $\mathrm{df}=$ $1 / 12, \mathrm{p}<.01)$ or Group ON $(\mathrm{F}=10.47, \mathrm{df}=1 / 12$, $p<.01$ ), but Groups $O N$ and $O P$ did not differ $(F<1.00)$. Combining the data from both experiments, on the first trial of position training, 12 of 16 animals given criterion training chose their previously preferred side, while only 7 of 16 animals given overtraining chose the preferred side $\left(\chi^{2}=2.125, \mathrm{df}=1, .10<\mathrm{p}<.20\right)$.

The major result is that overtraining on a visual discrimination did not produce inferior performance on a subsequent ED shift to a position discrimination. It has been hypothesized (cf. Sutherland \& Andelman, 1969) that overtraining on a visual discrimination decreases attention to irrelevant cues such as position. If so, then transfer from a visual to a spatial discrimination should be hindered by overtraining. Clearly, the results do not support the suggested hypothesis. In contrast to the expected detrimental effect, overtraining on the orientation discrimination led to superior performance when position training was to the nonpreferred side. A reasonable interpretation of the facilitative effect is that, rather than reducing attention to the position dimension, overtraining reduced the strength of instrumental preferences for preferred positions. In both experiments, animals transferred to their preferred position learned faster than those transferred to their nonpreferred position after criterion training but not after overtraining. Following overtraining, there was no difference in learning to approach preferred or nonpreferred positions. Further, there was a tendency for criterion-trained animals to choose their preferred side on the first transfer trial; there was no such tendency for overtrained animals. Thus, the facilitative effect of overtraining on ED shifts probably is due to a decrease in instrumental position preferences rather than in strength of attention.

\section{REFERENCES}

Clayton, K. N. The overlearning-reversal-effect: Dependent on a confound with drive? Paper presented at the Southeastern Psychological Association, Atlanta, Georgia, A pril 1965.

Hilgard, E. R. Methods and procedures in the study of learning. In S. S. Stevens (Ed.), Handbook of experimental psychology. New York: Wiley, 1951. Pp. 517-567.

Lovejoy, E. Attention in discrimination learning. San Francisco: Holden-Day, 1968.

Shepp, B. E., \& Turrisi, F. D. Learning and transfer of mediating responses in discriminative learning. In N. R. Ellis (Ed.), International review of research in mental retardation. New York: Academic Press, 1966. Pp. 85-121.

Sutherland, N. S., \& Andelman, L. Effects of overtraining on intra- and extra-dimensional shifts. Psychonomic Science, $1969,15,253-254$

Sutherland, N. S., \& Mackintosh, N. J. Mechanisms of animal discrimination learning. New York: Academic Press, 1971.

Wagner, A. R. Incidental stimuli and discrimination learning. In R. M. Gilbert and N. S. Sutherland (Eds.), Animal discrimination learning. New York: Academic Press, 1969. Pp. 83-111.

Waller, T. G. Facilitation of an extradimensional shift with overtraining in rats. Psychonomic Science, 1970, 20, 172-174.

Waller, T. G. The effect of overtraining on two extradimensional shifts in rats. Psychonomic Science, 1971, 23, 123-124.

Warren, J. M., \& McGonigle, B. Effects of differential and nondifferential reinforcement on generalization test performance by cats. Journal of Comparative \& Physiological Psychology, 1969, 69, 709-712. 
Zeaman, D., \& House, B. J. The role of attention in retardate discrimination learning. In N. R. Ellis (Ed.), Handbook of mental deficiency: Psychological theory and research. New
York: McGraw-Hill, 1963. Pp. 159-223.

(Received for publication June 5, 1972;

revision received September 19, 1972.) 